\title{
Investigating pharmaceutical marketing in Canada using American prosecutions
}

\author{
Rami Shoucri ${ }^{\mathrm{a}, \mathrm{b}}$ and Navindra Persaud ${ }^{\mathrm{a}, \mathrm{b}, \mathrm{c}, *}$ \\ ${ }^{a}$ Department of Family and Community Medicine, St Michael's Hospital, Toronto, ON, Canada \\ ${ }^{\mathrm{b}}$ Department of Family and Community Medicine, University of Toronto, Toronto, ON, Canada \\ ${ }^{\mathrm{c}}$ Keenan Research Centre in the Li Ka Shing Knowledge Institute, St Michael's Hospital, Toronto, ON, \\ Canada
}

Received 19 February 2014

Accepted 8 June 2014

\begin{abstract}
.
BACKGROUND: Pharmaceutical companies are prohibited from marketing medications for off-label uses in both the United States and Canada. In the United States, there have been several recent multi-billion dollar settlements with pharmaceutical companies based, partly, on off-label promotion. Health Canada has not publicized any investigations into, or prosecutions of, pharmaceutical companies for off-label promotion in Canada even though many of the same medications are marketed here. The prohibition on off-label promotion is largely directed at preventing pharmaceutical companies from circumventing the drug licensing process and attendant safety checks.

OBJECTIVE: To determine if sanctions for off-label pharmaceutical promotion in one jurisdiction can be used to regulate marketing in another.

METHODS: We reviewed and compared the laws and regulatory bodies in Canada and the United States to determine if Canadian regulators could use the findings of American regulators.

RESULTS: There were no important differences in the laws and regulatory bodies in Canada and the United States related to off-label promotion.

CONCLUSIONS: Canadian regulators can use the findings of American regulators to investigate off-label promotion in Canada. All countries should consider using sanctions in other jurisdictions to direct the deployment of limited regulatory resources.
\end{abstract}

Keywords: Pharmaceutical policy, off-label marketing

\section{Introduction}

In June of 2012, GlaxoSmithKline (GSK) was penalized nearly one billion dollars for misbranding paroxetine (Paxil) and buproprion (Wellbutrin) as part of a three billion dollar agreement with the Food and Drug Administration (FDA), the United States Department of Justice, and the United States Attorney for the District of Massachusetts ["the GSK-DOJ agreement"] [1]. Following the announcement of the GSK-DOJ agreement, an editorial in Nature concluded: "the US action is essential, one that other countries

\footnotetext{
*Address for correspondence: Navindra Persaud, 80 Bond Street, Toronto, ON, M5B 1X2, Canada. Tel.: +1 4168643011 ; Fax: +1 416 8643099; E-mail: nav.persaud@ utoronto.ca. 
can follow as a model and a landmark on the road to making corporate responsibility less of a slogan, and more of a reality" [2]. Here, we examine what, if any, action the American penalty should prompt in Canada where paroxetine and buproprion continue to be marketed?

The GSK-DOJ agreement, which had its origins in investigations into the marketing practices for nine medications started by the US Attorney's Office in 2004, is one of several recent sizable reprimands of pharmaceutical companies in the United States. In January of 2009 Eli Lilly was fined 1.4 billion dollars for the off-label promotion of olanzapine [Zyprexa] [3], AstraZeneca agreed to pay 520 million dollars in April 2010 after an investigation of the off-label promotion of quetiapine [Seroquel] [4], and in July of 2012 Abbot was fined 1.5 billion for the off-label promotion of long acting valproic acid [Depakote] [5]. In addition to the guilty pleas related to paroxetine and buproprion, the GSK-DOJ agreement included criminal fines and civil settlements of more than two billion dollars for the failure to submit important safety information regarding rosiglitazone (Avandia) and for underpayment of rebates required by the Medicaid program [1].

Although these cases relate to sanctions for a variety of offenses, this article will focus on the penalties imposed on GSK with respect to the marketing of Wellbutrin and Paxil as examples of the prohibition of off-label promotion of pharmaceutical products for the purposes of highlighting similarities and differences between the American and Canadian political, legal, and regulatory frameworks. We find that the policy imperatives and the legislative frameworks are indeed similar enough between the United States and Canada such that censures of pharmaceutical companies by American regulators could prompt similar investigations here in Canada, although there would have to be investments in the regulatory infrastructure and a review of the available penalties available in Canada to make such prosecutions viable and effective.

\section{Pharmaceutical regulation - American context}

The FDA has been requiring evidence of safety before allowing a drug on the market since 1938. It has only been empowered to evaluate evidence of efficacy in the decision to allow drugs onto the market since 1962 [6]. Importantly, the FDA's authority does not extend to the regulation of off-label prescribing of medications by physicians. The issue for discussion here is the regulation of the communication of off-label use of medication by pharmaceutical companies to physicians.

In the GSK-DOJ agreement, for example, GSK pleaded guilty to two charges of "delivery for introduction into interstate commerce" of a "misbranded" drug in violation of section 331(a) of the Federal Food, Drug and Cosmetic Act [7]. GSK admitted to marketing Paxil as a safe and effective anti-depressant for teenagers although Paxil was not indicated for pediatric use and that it had promoted Wellbutrin for off-label purposes such as obesity, addiction, and ADHD, whereas the labels did not include appropriate warnings for such uses (Table 1).

In general, regulations are necessary to provide more detailed guidance for the implementation of statutes. As may be apparent from the above discussion, the FDA relies on jurisdiction over labeling to regulate the marketing of pharmaceuticals. The Act defines labels as including materials "accompanying" the product [8]. The Supreme Court of the United States has elsewhere elaborated on the definition of "accompanying" to include materials that may not necessarily actually physically accompany the product but that also share a "common origin and a common destination" [9]. On this basis, the regulations applicable to the FDA's authority includes jurisdiction over a broad range of marketing tools and practices for medications. 
Table 1

Comparison of American and Canadian Legal/Regulatory Basis for Regulation of Off-Label Pharmaceutical Promotion

\begin{tabular}{|c|c|c|}
\hline & $\begin{array}{l}\text { American } \\
\text { Food, Drug and Cosmetic Act }\end{array}$ & $\begin{array}{l}\text { Canadian } \\
\text { Food and Drug Act (FDAct) }\end{array}$ \\
\hline \multirow[t]{3}{*}{$\begin{array}{l}\text { Foundational } \\
\text { legislation }\end{array}$} & $\begin{array}{l}\text { S. 331(a): "delivery for introduction into } \\
\text { interstate commerce" of a "misbranded" drug }\end{array}$ & Deception, etc., regarding drugs: \\
\hline & $\begin{array}{l}\text { S. } 352 \text { (a): "a drug ... shall be deemed to be } \\
\text { misbranded if it's labeling is false or misleading } \\
\text { in any particular." }\end{array}$ & $\begin{array}{l}\text { 9. (1) No person shall label, package, treat, } \\
\text { process, sell or advertise any drug in a manner } \\
\text { that is false, misleading or deceptive or is likely } \\
\text { to create an erroneous impression regarding its } \\
\text { character, value, quantity, composition, merit or } \\
\text { safety. }\end{array}$ \\
\hline & $\begin{array}{l}\text { S. 352(f), a medication will be deemed to be } \\
\text { misbranded if its label does not bear "such } \\
\text { adequate warnings against use in those } \\
\text { pathological conditions or by children where its } \\
\text { use may be dangerous to health, or against } \\
\text { unsafe dosage or methods or duration of } \\
\text { administration or application, in such manner } \\
\text { and form, as are necessary for the protection of } \\
\text { users." }\end{array}$ & $\begin{array}{l}\text { (2) A drug that is not labelled or packaged as } \\
\text { required by, or is labelled or packaged contrary } \\
\text { to, the regulations shall be deemed to be } \\
\text { labelled or packaged contrary to subsection (1) }\end{array}$ \\
\hline \multirow[t]{2}{*}{ Regulation } & $\begin{array}{l}\text { Food, Drug and Cosmetic Act Regulations } \\
\text { 21C.F.R. } \S 202.1(1)(2)(2011) \text {. }\end{array}$ & $\begin{array}{l}\text { Food and Drug Regulations C.R.C., c. } 870 \text { current } \\
\text { to December 10, 2012. At } \\
\text { http://laws-lois.justice.gc.ca }\end{array}$ \\
\hline & $\begin{array}{l}\text { FDA's authority includes jurisdiction over a broad } \\
\text { range of marketing tools and practices for } \\
\text { medications, including "brochures, booklets, } \\
\text { mailing pieces ... bulletins, calendars, price } \\
\text { lists, catalogues" etc }\end{array}$ & $\begin{array}{l}\text { C.08.006 (2) The Minister may, by notice to a } \\
\text { manufacturer, suspend, for a definite or } \\
\text { indefinite period, a notice of compliance issued } \\
\text { to that manufacturer in respect of a new drug } \\
\text { submission... if the Minister considers (f) that, } \\
\text { on the basis of new information obtained after } \\
\text { the issuance of the notice of compliance, the } \\
\text { labeling of the drug is false or misleading or } \\
\text { incomplete in any particular }\end{array}$ \\
\hline \multirow{2}{*}{$\begin{array}{l}\text { Most Responsible } \\
\text { Institution }\end{array}$} & Food and Drug Administration & Health Canada, Regulatory Advertising Section \\
\hline & & $\begin{array}{l}\text { Marketed Health Products Directorate } \\
\text { Health Products and Food Branch }\end{array}$ \\
\hline
\end{tabular}

The investigation regarding GSK clearly required a massive investment of resources by American authorities. When announcing the agreement, the press release issued by the federal government placed it primarily in the context of an overall effort to eliminate fraud in the health care system [10]. That is, as important as the safety considerations were in this initiative, it may be argued that much of the political will for the investigation and prosecution in America was derived from the drive to bring down soaring health care costs, an imperative that is also pressing in Canada. 


\section{Canadian context}

The advertising of pharmaceuticals in Canada is largely regulated by the Federal Food and Drug Act (FDAct) [11]. Health Canada is ultimately responsible for the enforcement of the legislation, although there are three agencies, known as advertising pre-clearance agencies (APAs), that provide voluntary drug advertising material review services to pharmaceutical companies: the Pharmaceutical Advertising Advisory Board (PAAB); Advertising Standards Canada (ASC); and the private company MIJO, the latter two agencies offering services for over the counter medications [12].

A detailed review of the permissibility of a particular promotional activity involves examining several levels of authority, including; (1) the foundational legislation (the FDAct primarily) and the relevant constitutional restraints; (2) the regulations created under the act; (3) the guidelines produced by Health Canada in relation to the legislation and regulations; (4) the codes produced by APAs intended to facilitate compliance with these laws, regulations and guidelines; (5) and the industry's own code of conduct.

With respect to the promotion of pharmaceuticals in particular, the FDAct is quite brief yet broad, with the overall framework outlined in section nine. In contrast to the American foundational legislation, the prohibition on "deception" in the FDAct explicitly extends to advertising and not merely to mislabeling, although there is no explicit use of the term "off-label promotion." The associated regulations are similarly non-specific with respect to the promotion of "off-label" uses of pharmaceutical products but all policies and guidelines emanating from each of Health Canada, the APAs, and even the pharmaceutical industry's own self-regulating policies very clearly endorse a prohibition on the promotion of off-label uses of medications [13]. The controversy, however, lies in distinguishing promotional communications from non-promotional communication such as for the purposes of education and scientific analysis [14].

The primary remedy detailed in FDAct regulations is the suspension or withdrawal of "the notice of compliance" for a particular pharmaceutical product by Health Canada although there is no authority to levy significant fines as has been done in the United States [15].

\section{Analysis}

There is sufficient overlap between Canadian and American pharmaceutical regulation policy objectives and legislative framework to pursue similar actions against pharmaceutical companies in Canada as those recently concluded in the United States, although they would face similar legal and political obstacles. What is less clear, however, is whether there is the same political will and regulatory infrastructure in terms of the authority to impose a significant financial penalty on pharmaceutical companies for violations and the human resources in Health Canada to investigate and prosecute potential violations, to do so in Canada.

\section{Should off-label marketing be investigated in Canada?}

The policy of prohibiting off-label promotion of medications is justified broadly on the basis of safety. The rationale is that medications that have not been approved for specific indications are more likely to cause harm and, furthermore, they would be more likely used off-label if there was widespread promotion of this use. In analyzing this argument, it is important to distinguish the variety of practices that fall under the rubric of "off-label" use, which can range from "from fairly minor deviations from specified dosage to usage in entirely different conditions." The usage might range anywhere from the "standard of care ... or acts of desperation ... to ad hoc experimentation, or dangerous misuses of drugs prompted by surreptitious 
marketing efforts by their manufacturers" [16]. The policy dilemma is how to minimize the risk of the latter practices while neither preventing the useful flow of information for the less worrisome former practices nor infringing upon corporate free speech rights.

The current regulatory framework in both Canada and the United States attempts to strike this policy balance by distinguishing between communication for the purposes of education from communication for the purposes of promotion to minimize the risk of stifling the flow of useful and truthful information. Some American scholars have suggested that pharmaceutical companies may succeed on first amendment challenges on the basis that the ban on promotional communication of off-label use is overly broad. These scholars point out that the first amendment, which broadly protects free speech, already prohibits false or misleading speech, regardless of whether it is about off-label or on-label use, and that this veracity should be the focus of regulation. A variation of this argument has just succeeded in a New York Appeals court, although with one dissenting judge, $[17,18]$ and a similar argument could likely be made based on Canadian constitutional law. The approach proposed by these critics, however, would shift the responsibility to ensure consistency between drug indications and scientific evidence from, on the one hand, the pharmaceutical companies pursuant to the already existing licensing process, to, on the other hand, regulators and, by extension, taxpayers, via a brand new stream of regulation.

\section{How should investigations be financed?}

Given the sheer volume of promotional and educational activities that pharmaceutical companies pursue in this country, thorough regulation would require a significant investment of time and resources. Three criteria for evaluating funding systems have been proposed: (1) stability of funding; (2) predictability of funding; and (3) lack of perverse ties between the level of financing and performance [19]. The current Canadian model for funding the print pre-clearing agencies, primarily the $\mathrm{PAAB}$, is through payments by pharmaceutical companies based on the amount of promotional materials they produce. Using these criteria, this system of financing scores fairly well in the stability and predictability of the funding but it raises concerns about the independence of the agency given the close ties engendered by the funding arrangement. The issue of off-label promotion does not, by definition, fall within the currently accepted mandate of the pre-clearing advertising agencies. However, Health Canada has the overarching jurisdiction to enforce all elements of the FDAct. It has, in fact, established a division with the mandate to specifically monitor the promotional activities of pharmaceutical companies, with its guiding principle in deciding to prosecute or not being the overall risk to public safety [20], although the staffing of the office does not appear to be sufficient to manage such investigations and prosecutions. An initial investment in the infrastructure of this division is likely necessary to build the capacity to pursue these investigations, after which we would suggest that the regime could be supported with the fines collected, although there should also be some steady public funding to minimize the risk of perverse incentives for investigators to prosecute merely to sustain the system.

\section{Conclusion}

The GSK-DOJ agreement, like other recent multi-billion dollar agreements with pharmaceutical companies in the United States, related to medications that are widely prescribed in Canada. In the future, Health Canada could automatically trigger an investigation of the marketing of a particular medication once it is known that it was illegally promoted in the Unites States. Of course, not every American finding 
of wrongdoing will be replicated in Canada but such mirror investigations might be more efficient to execute than others because they could focus on the issues identified by American officials. For example, the fact that GSK admitted to marketing Paxil off-label as a safe and effective anti-depressant for teenagers and to promoting Wellbutrin for off-label purposes such as obesity, addiction, and ADHD in the United States seems like a fruitful starting point for an investigation into the practices of the Canadian branch of GSK which markets those same two medications in Canada. The investigative machinery could be primarily funded by the fines and settlements from investigations, which would concentrate the burden of paying for marketing regulation on those pharmaceutical companies that flaunt the rules. The ultimate goal is a safer prescribing environment where pharmaceutical companies are incentivized to pursue the potentially costly task of getting a new indication approved by Health Canada, a process which involves crucial safety and efficacy reviews.

\section{Acknowledgements}

We thank Irfan Dhalla and Joel Lexchin for comments on an earlier draft.

\section{Author contributions}

NP conceived of the idea and wrote the first draft, RS did the legal research and wrote the second draft. Both authors approved the final version.

\section{References}

[1] The United States Department of Justice [Internet]. Re: United States. v. GlaxoSmithKline LLC. [accessed 31 July 2012] Available from: http://www.justice.gov/opa/documents/gsk/plea-agreement.pdf

[2] Take a Stand [Editorial]. Nature. 2012;487:139-40.

[3] The United States Department of Justice [Internet]. Eli Lilly and Company Agrees to Pay \$1.415 Billion to Resolve Allegations of Off-label Promotion of Zyprexa. [accessed 31 July 2012] Available from: http://www.justice. gov/opa/pr/2009/January/09-civ-038.html x

[4] The United States Department of Justice [Internet]. Pharmaceutical Giant AstraZeneca to Pay \$520 Million for Off-label Drug Marketing. [accessed 31 July 2012] Available from: http://www.justice.gov/opa/pr/2010/April/10-civ-487.html

[5] The United States Department of Justice [Internet]. Abbott Labs to Pay \$1.5 Billion to Resolve Criminal \& Civil Investigations of Off-label Promotion of Depakote. [accessed 31 July 2012] Available from: http://www.justice.gov /opa/pr/2012/May/12-civ-585.html

[6] Conko G. Hidden truth: The perils and protection of off-label drug and medical device promotion. Health Matrix: Journal of Law and Medicine. 2011;(21):149.

[7] Food, Drug, and Cosmetic Act. 21 U.S.C. $\S 301$ et seq.

[8] Food, Drug, and Cosmetic Act Regulations. 21C.F.R. §202.1[1][2][2011]

[9] Kordel v. United States, 335 U.S. 345, 348-350 1948.

[10] The United States Department of Justice [Internet]. Deputy Attorney General James M. Cole Speaks at the GSK Press Conference. [accessed 31 July 2012] Available from: http://www.justice.gov/iso/opa/dag/speeches/2012/dag-speech1207021.html

[11] Food and Drugs Act. R.S.C., 1985, c. F-27.

[12] Pharmaceutical Advertising 2012 - Canada Chapter. Mondaq Business Briefing 10 July 2012.

[13] Canada's Research Based Pharmaceutical Companies ["Rx \& D"] [Internet]. Code of Ethical Practices. [accessed January 23, 2013] Available from: http://www.canadapharma.org/CMFiles/Commitment_to_Ethics/WithHealthCareProfes sionals/Code_of_Ethical_Practices/2012_CodeofEthicalPractices_ENFinal.pdf 
[14] Health Canada [Internet]. Ottawa (ON): Health Canada: [Updated August 2005]. The Distinction Between Advertising and Other Activities. Issued: January 12, 1996. Available from: http://www.hc-sc.gc.ca/dhp-mps/advert-publicit/ pol/actv_promo_vs_info-eng.php

[15] Food and Drug Regulations C.R.C., c. 870

[16] Noah L. "Truth or Consequences?: Commercial Free Speech vs. Public Health Promotion [at the FDA]." Public Health Promotion [at the FDA] [August 12, 2010]. Health Matrix: Journal of Law-Medicine. 2011;21:31.

[17] Boumil M. Off-label marketing and the first amendment. N Engl J Med. 2013;368;2. 103.

[18] United States Court of Appeals for the Second Circuit. United States. v. Caronia 2013 [Internet]. [accessed March 3, 2013] Available from: http://www.hpm.com/pdf/blog/Caronia\%202d\%20Circuit\%20Slip\%20Opinion.pdf

[19] Lexchin, J. Models for financing the regulation of pharmaceutical promotion. Globalization and Health. 2012;8:24.

[20] Health Canada [Internet]. Ottawa [ON]: Health Canada: [Updated 2009-11-25]. Compliance and Enforcement Policy. Available from: http://www.hc-sc.gc.ca/dhp-mps/compli-conform/gmp-bpf/pol/pol_1_tc-tm-eng.php 